\title{
An alternative method of anaesthesia for implant insertion: description of a clinical initiative in contraceptive care
}

\author{
Julia Shefras, ${ }^{1}$ Annabel Forsythe, ${ }^{2}$ Fatima Nathani, ${ }^{3}$ Donna Hoffman ${ }^{4}$
}

${ }^{1}$ Consultant in Contraception and Sexual Health, C\&SH Oxford Health NHS Foundation Trust, The Alec Turnbull Centre, Oxford, UK

${ }^{2}$ Specialist Trainee in Community Sexual \& Reproductive Health, Department of Contraception \& Sexual Health, Oxford Health NHS Foundation Trust, Oxford, UK

${ }^{3}$ Consultant in Contraception and Sexual Health, Russells Hall Hospital, Dudley Group of Hospitals, Dudley, UK

${ }^{4}$ Clinical Nurse Specialist in Contraception and Sexual Health, Oxford Health NHS Foundation Trust, Oxford, UK

\section{Correspondence to}

Dr Julia Shefras, Department of Contraception \& Sexual Health, Oxford Health NHS Foundation Trust, The Alec Turnbull Centre, 23 Between Towns Road, Oxford OX4 3JH, UK; julia. shefras@oxfordhealth. nhs.uk

Received 16 July 2013 Revised 10 December 2013 Accepted 12 December 2013 Published Online First

5 February 2014

\section{CrossMark}

To cite: Shefras J, Forsythe A, Nathani F, et al. J Fam Plann Reprod Health Care 2014:40:226-228.

\section{WHAT IS THE CURRENT ANAESTHETIC PRACTICE FOR IMPLANT INSERTIONS?}

Adequate anaesthesia is an important procedural step when inserting contraceptive implants. Whilst the product information for Nexplanon ${ }^{\circledR}$ describes a choice of anaesthetic spray or injection for insertion, ${ }^{1}$ the Faculty of Sexual \& Reproductive Healthcare (FSRH) does not mention spray, solely recommending use of lidocaine injection. ${ }^{2}$ Therefore anaesthetic spray such as ethyl chloride, despite being a recognised technique for implant insertions, is not widely used.

\section{WHAT IS ETHYL CHLORIDE SPRAY?}

Ethyl chloride spray acts as a local anaesthetic when sprayed onto the skin. It is a fast acting vapo-coolant with minimal side effects and it can be safely used for sterile procedures with no additional risk of bacterial contamination. ${ }^{3}$ It is a longestablished analgesic technique for insertion of cannulas and needles, particularly in paediatric care.

\section{WHY IS AN ALTERNATIVE ANAESTHESIA NEEDED?}

Lidocaine injection provides effective anaesthesia, but may cause some discomfort during injection. It involves the cost, storage and management of needles, syringes, sharps disposal and local anaesthetic. Furthermore, the time taken to gather and prepare these items and then dismantle the trolley represents the greater part of the overall process.

The aim of this project was to evaluate whether use of ethyl chloride spray as an alternative anaesthetic for insertion of contraceptive implants is an innovation offering improvement for patients, increased productivity for the service and potentially cost savings in comparison to use of lidocaine.

\section{HOW WAS THE CHANGE IMPLEMENTED?}

During a 6-month period commencing January 2012, 4 of 16 implant fitters in the Oxford Health C\&SH service offered a choice of spray or lidocaine injection for implant insertions. During this time, an evaluation of patients' experiences was performed. Alongside this a comparative evaluation of the two methods by all staff fitting implants was also undertaken in a non-clinical environment. Following the results, training in the technique was cascaded to all implant fitters and spray is now offered by all fitters within Oxford Health C\&SH services.

\section{HOW HAVE PATIENTS FOUND THE USE OF ETHYL CHLORIDE SPRAY?}

Four clinicians trained in use of ethyl chloride spray saw 25 clients for implant insertions. They offered clients the choice of spray or injection for the insertion. Afterwards the clients were invited to complete a questionnaire.

The clients were in the age range 1448 (median 22) years. Ten had used an implant in the past, inserted with local anaesthetic injection. Fifteen were having an implant fitted for the first time. Four clients chose to have the injection (two first-time users and two previous users).

Twenty-three clients felt the procedure was comfortable, two felt it was uncomfortable (one spray, the other injection). Comfort ratings ranged from 2 to 10 (average, 7.6) with 10 being the best health state, 0 being the worst health state. Twenty-three clients said they would recommend the procedure to a 
friend; two would not (the same two who felt the procedure was uncomfortable).

Of the eight clients who had a previous insertion with injection followed by spray this time, none felt the procedure was more painful, with five rating the comfort level as 'the same' and three as 'more comfortable' than the previous insertion.

Comments from clients included "felt fine", "fantastic", "painless and quick" and "use spray!". There was one negative comment "it hurt" by a client who had spray and was one of the two who said the procedure was uncomfortable.

\section{HOW HAVE STAFF FOUND USING ETHYL CHLORIDE SPRAY?}

Before training was cascaded throughout the service all fitters were invited to participate in a comparative evaluation of anaesthesia in a non-clinical environment. Each participant was shown two photographs (Figures 1 and 2) that demonstrated the items

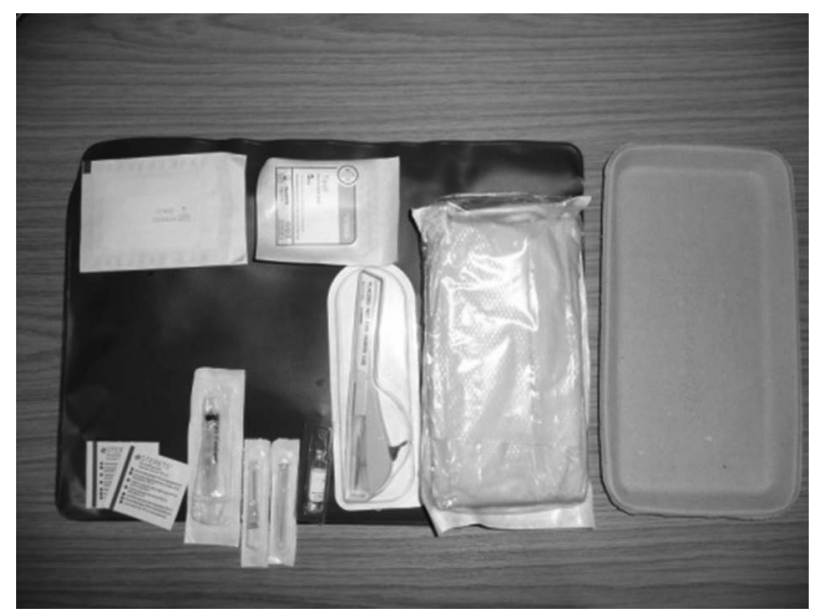

Figure 1 Items routinely available for implant fitting using lidocaine.

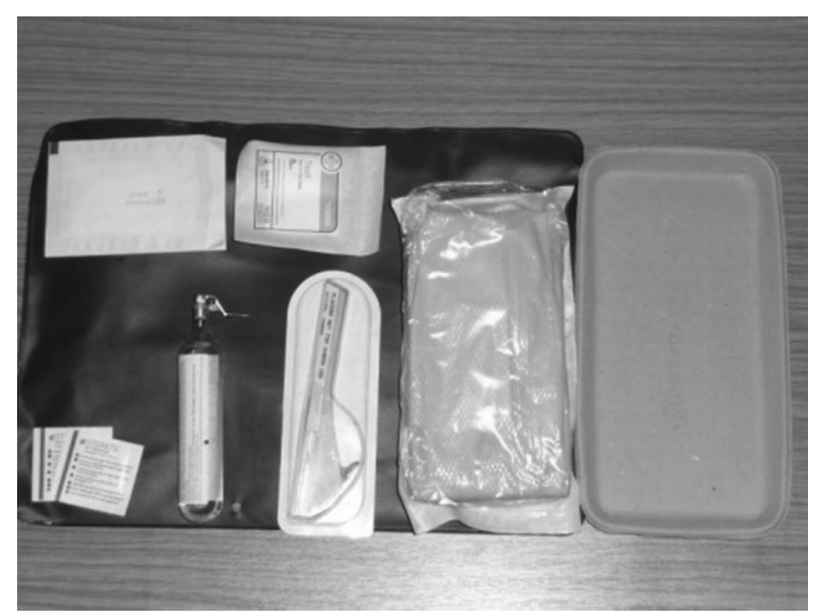

Figure 2 Items routinely available for implant fitting using ethyl chloride spray. routinely available for implant fitting with the anaesthetic options. They were timed to set up and then dismantle a trolley as if they were fitting an implant with one type of anaesthesia. They were then asked to repeat the process as if they were using the other and fill in an evaluation form.

Of the 15 fitters, four staff members were offering spray as part of their routine practice and the remainder were using lidocaine. The average times to set up and dismantle a trolley for injection and spray were 147.6 (range 98-230) seconds and 60.67 (range 30$127)$ seconds, respectively. The process with spray was on average 1 minute 27 seconds (60\%) faster.

All staff rated spray preparation as 'easy'. Eight staff members rated lidocaine as 'easy' and seven as 'reasonable'. When asked to rank anaesthetics, 12 preferred spray, two favoured lidocaine and one found them equally acceptable. Table 1 summarises staff comments regarding use of spray.

Following the initial staff evaluation and patient survey, a procedure was developed and the technique was taught to all staff fitting implants within the service.

\section{COULD THERE BE ANY COST SAVINGS?}

Based on current practice within the service, we estimate a minimum saving of $£ 117.80 / 1000$ patients using ethyl chloride spray in place of lidocaine injection.

\section{WHAT ARE POTENTIAL ADVANTAGES AND DISADVANTAGES OF ETHYL CHLORIDE SPRAY?}

The client audit suggests that both techniques are acceptable and provide adequate levels of anaesthesia.

No adverse effects were reported from use of spray. It does not require a patient group direction. It does not carry a risk of allergy and systemic overdose, but manufacturers advise that over-cooling of the skin by prolonged use carries a risk of frostbite and that ethyl chloride spray should not be used on broken skin, wounds or in skin conditions such as eczema. ${ }^{3}$ Furthermore, the anaesthetic effect of the spray wears off after 1 minute so insertion needs to be within 45 seconds of use, necessitating correct set up and efficiency.

Verbal reports from staff suggest less bleeding/bruising with spray, which may be an additional benefit arising from the vasoconstrictive properties of a coolant in combination with fewer needle insertions.

The relative speed of using spray may encourage more quick-starting to take place, facilitating one-stop care and fewer second visits. Although initial savings based on equipment are modest, savings on a grander scale may be predicted if it helps to reduce follow-up appointments and possibly unintended pregnancies. 
Better way of working

Table 1 Staff comments, concerns and suggestions about use of ethyl chloride spray

\begin{tabular}{lll}
\hline Positive comments & Negative comments/concerns & Suggestions \\
\hline Easier & Anxious about having to rush insertion before spray wears off & Would like guidance from FSRH \\
Time efficient & Worried about not giving enough spray & Would like spray to be readily available \\
Cost efficient & Can frozen skin restrict glide? & Would like a protocol \\
Less risk of needlestick & Lidocaine gives longer to chat to patient and type up notes & \\
Appears less painful for patient & & \\
Good for the needle phobic & & \\
\hline FSRH, Faculty of Sexual \& Reproductive Healthcare.
\end{tabular}

\section{WHAT COULD THE FUTURE HOLD?}

Use of ethyl chloride spray has potential to improve both quality of care, patient choice and productivity. It may offer additional clinical advantages and cost savings.

Lidocaine remains the anaesthetic of choice for implant removals due to the need for a longer duration of action for this procedure.

Competing interests None.

Provenance and peer review Not commissioned; externally peer reviewed.

\section{REFERENCES}

1 Organon Laboratories Ltd. Nexplanon - Information for healthcare professionals. Last approved July 2012.

2 Faculty of Sexual \& Reproductive Healthcare Clinical Effectiveness Unit. Progestogen-only Implants. April 2008 (updated January 2009). http://www.fsrh.org/pdfs/ CEUGuidance ProgestogenOnlyImplantsApril08.pdf [accessed 2 June 2013].

3 Acorus Therapeutics Ltd. Ethyl Chloride EEC Safety Data Sheet. 2001 (updated 2007). 